\title{
Analysis of Medical Disputes and Compensation Costs Associated With Gastric Cancer Surgery at a Large-volume Center
}

\author{
Amy Kim \\ Korea University Ansan Hospital https://orcid.org/0000-0002-7021-9214 \\ Moon Won Yoo ( $\nabla$ medigang@hanmail.net) \\ University of Ulsan College of Medicine https://orcid.org/0000-0003-0346-9042
}

\author{
Research \\ Keywords: Compensation, Malpractice, Gastric cancer \\ Posted Date: June 9th, 2021 \\ DOI: https://doi.org/10.21203/rs.3.rs-589733/v1 \\ License: () (7) This work is licensed under a Creative Commons Attribution 4.0 International License. Read Full License
}




\section{Abstract}

Background

The incidence and costs of medical disputes in Korea are increasing annually. The purpose of this study was to identify the characteristics of medical dispute cases and analyze compensation costs in gastric cancer patients who were admitted for surgery at a single large-volume center.

Methods

Gastric cancer patients who were admitted for surgery and received compensation after filing medical disputes with the legal affairs team at our center between January 2012 and December 2017 were retrospectively registered for the study. The characteristics of and information on the disputes were reviewed and the amount of awarded compensation was analyzed according to different factors.

Results

There were 20 cases of medical disputes associated with gastric cancer surgery during the study period. In five cases, evidence of medical negligence was detected. There were 17 morbidity cases and four mortality cases. The mean compensation cost paid for settlement was USD 7,502. Length of hospital stay $(p=0.009)$ and morbidity $(p=0.004)$ were significantly associated with compensation.

Conclusion

Our results demonstrate foundational information on disputes regarding surgery in gastric cancer patients and the accompanying compensation costs for settlement.

\section{Background}

Surgery plays a key role in the treatment of gastric cancer because it is the only option that can achieve a cure(1). Nevertheless, recent reports have demonstrated that gastrectomy is associated with significant postoperative complications(2-4). A multicenter retrospective study conducted by the Korean Laparoscopic Gastrointestinal Surgery Study group for preoperative stage I gastric cancer in Korea reported overall morbidity and mortality rates of $14 \%$ and $0.6 \%$, respectively(5).

Although some complications following gastrectomy are inevitable, patients may be dissatisfied with the outcomes. Medical disputes and litigation are increasing in Korea, and these are often related to surgery, with 1,907 applications for medical dispute mediation in 2016, showing a mean annual increase of $30.5 \%$. Of the 1,907 cases, $44.7 \%$ were related to surgery(6). According to a recent report that investigated cases of lawsuits related to surgery in Korea, of 81 cases during the five years between 2005 and 2010, 23 cases were related to gastrointestinal surgery(7).

While the number of medical disputes has increased rapidly(6), details on the characteristics of disputes associated with gastric surgery or compensation have never been addressed in previous studies.

This study aimed to identify and analyze the current status of medical disputes associated with gastrectomy in patients with gastric cancer based on a singlecenter experience.

\section{Methods}

This study is a retrospective analysis of medical disputes in gastric cancer patients who were admitted for surgery during the six years between January 2012 and December 2017 at Asan Medical Center. Only cases in which compensation was awarded to the patient for resolution of the dispute were included in the study. The list of patients involved and the amount of monetary compensation awarded were shared by the legal affairs team at our center, and the electronic medical charts were reviewed for data collection.

To evaluate patient characteristics, data on sex, age, past medical history, details of the operation including operation name, date and combined operation, postoperative complications, or other problems during the hospital stay, the detection date, hospital stays, and survival were collected and analyzed.

Complications or other events that caused the medical disputes were categorized into three groups: surgical complications, medical complications, and other events. Adverse events were ranked according to the Clavien-Dindo classification (CDC)(8). Morbidity was defined as any adverse event classified as CDC grade III-V or other events that led to equivalent consequences. Hospital stays were counted since the day patients' chief complaints for disputes occurred and any additional admissions within 30 days related to the event were also counted for the summation of the total stay at the hospital. The presence of medical negligence was determined by two different gastrointestinal surgeons. All estimated costs are represented in U.S. dollars (USD), using the 2018 annual exchange rate of $1,100 \mathrm{KRW}$ to USD 1.

Statistical analysis was performed using SPSS version 25.0 (SPSS, Inc., Chicago, IL, USA). To compare the amount of awarded compensation depending on different factors, the Mann-Whitney $\mathrm{U}$ test or Kruskal-Wallis $\mathrm{H}$ test and Spearman's rank-order correlation test were used for categorical and continuous variables, respectively. Statistical significance was set at $p<0.05$.

The study was approved by the Institutional Review Board of Asan Medical Center (registration number: 2020 - 0993)

\section{Results}


There was a total of 20 cases of medical disputes associated with gastric cancer surgery during the study period. All cases were managed by the legal affairs team at the hospital, and none progressed to lawsuits. The baseline characteristics and details of the complications or other problems patients complained of as the cause of disputes is described in Table 1.

Table 1

The clinical details of gastric cancer patients who received medical compensation for settlement of medical disputes.

\begin{tabular}{|c|c|c|c|c|c|c|c|c|c|c|c|c|}
\hline $\begin{array}{l}\text { Case } \\
\text { No. }\end{array}$ & Sex & Age & $\begin{array}{l}\text { Past medical } \\
\text { history }\end{array}$ & $\begin{array}{l}\text { Operation } \\
\text { name }\end{array}$ & $\begin{array}{l}\text { Combined } \\
\text { operation }\end{array}$ & $\begin{array}{l}\text { Complications } \\
\text { or other } \\
\text { problems } \\
\text { leading to } \\
\text { disputes }\end{array}$ & $\begin{array}{l}\text { Day of } \\
\text { detection } \\
\text { (postoperative } \\
\text { days) }\end{array}$ & $\mathrm{CDC}$ & Negligence & $\begin{array}{l}\mathrm{Re}- \\
\text { operation }\end{array}$ & Mortality & $\begin{array}{l}\text { Ho: } \\
\text { sta }\end{array}$ \\
\hline 1 & M & 70 & NAFLD & LDG & LAR & Leakage & 19 & Illb & No & Yes & No & 72 \\
\hline 2 & M & 72 & $s / p$ LAR, LC & LDG & DP & $\begin{array}{l}\text { Postoperative } \\
\text { ileus }\end{array}$ & 99 & Illb & No & Yes & No & 10 \\
\hline 3 & M & 71 & & LTG & & Leakage & 4 & Illa & No & No & No & 78 \\
\hline 4 & M & 46 & Schizophrenia & LTG & & Leakage & 6 & II & No & No & No & 32 \\
\hline 5 & M & 66 & & & & Anaphylaxis & 0 & IV & No & No & No & 11 \\
\hline 6 & $\mathrm{~F}$ & 72 & $\begin{array}{l}\text { Parkinson's } \\
\text { disease } \\
\text { s/p LDG }\end{array}$ & TG & & $\begin{array}{l}\text { Postoperative } \\
\text { ileus }\end{array}$ & 90 & V & Yes & Yes & Yes & 31 \\
\hline 7 & M & 31 & & DG & & $\begin{array}{l}\text { Postoperative } \\
\text { ileus }\end{array}$ & 14 & Illb & No & Yes & No & 13 \\
\hline 8 & $M$ & 42 & & DG & & $\begin{array}{l}\text { Postoperative } \\
\text { ileus }\end{array}$ & 9 & Illb & No & Yes & No & 20 \\
\hline 9 & M & 67 & $s / p$ LT & DG & & $\begin{array}{l}\text { Incomplete } \\
\text { resection }\end{array}$ & 0 & Illb & Yes & Yes & No & 13 \\
\hline 10 & M & 73 & & TG & & PCA errors & 0 & NA & No & No & No & 9 \\
\hline 11 & M & 61 & & LTG & & $\begin{array}{l}\text { latrogenic injury } \\
\text { of small bowel }\end{array}$ & 2 & Illb & Yes & Yes & No & 11 \\
\hline 12 & $\mathrm{~F}$ & 72 & h/o stroke & LDG & & $\begin{array}{l}\text { Intraabdominally } \\
\text { retained drain }\end{array}$ & 4 & IIllb & Yes & Yes & No & 5 \\
\hline 13 & M & 67 & $\begin{array}{l}\text { Hypertension, } \\
\text { DM }\end{array}$ & LDG & & $\begin{array}{l}\text { Acute } \\
\text { myocardial } \\
\text { infarction }\end{array}$ & 4 & V & No & No & Yes & 1 \\
\hline 14 & $M$ & 64 & & TG & & Leakage & 6 & II & No & No & No & 31 \\
\hline 15 & $\mathrm{~F}$ & 39 & & LTG & & Leakage & 2 & Illb & No & Yes & No & $14 t$ \\
\hline 16 & M & 54 & $\begin{array}{l}\text { Aortic } \\
\text { dissection }\end{array}$ & & & Anaphylaxis & 0 & V & No & No & Yes & 44 \\
\hline 17 & $\mathrm{~F}$ & 79 & & TG & & $\begin{array}{l}\text { Postoperative } \\
\text { bleeding }\end{array}$ & 5 & V & No & No & Yes & 2 \\
\hline 18 & $\mathrm{~F}$ & 72 & Asthma & DG & & $\begin{array}{l}\text { Postoperative } \\
\text { bleeding }\end{array}$ & 1 & IV & No & Yes & No & $23 c$ \\
\hline 19 & $\mathrm{~F}$ & 54 & & TG & & $\begin{array}{l}\text { Postoperative } \\
\text { ileus }\end{array}$ & 6 & IIllb & No & Yes & No & 20 \\
\hline 20 & M & 74 & Hypertension & LDG & LC & $\begin{array}{l}\text { latrogenic injury } \\
\text { of CBD }\end{array}$ & 3 & Illb & Yes & Yes & No & 23 \\
\hline
\end{tabular}

$C D C=$ Clavien-Dindo classification; NAFLD = nonalcoholic fatty liver disease; $L D G=$ laparoscopic distal gastrectomy; $L A R=$ low anterior resection; $D P=$ distal pancreatectomy; LTG = laparoscopic total gastrectomy; DG = distal gastrectomy; TG = total gastrectomy; $L C=$ laparoscopic cholecystectomy; PCA = patientcontrolled analgesia; $\mathrm{LT}=$ liver transplantation; $\mathrm{CBD}=$ common bile duct

The events that patients complained of as the main cause for the disputes are summarized in Table 2 . There were 14 (70.0\%) cases related to surgical complications, including five cases of anastomotic leakage, two cases of bleeding, five cases of mechanical ileus, one case of iatrogenic injury of small bowel and a case of iatrogenic injury of common hepatic duct. Medical complications included two cases of anaphylaxis that occurred during the induction of anesthesia and a case of acute myocardial infarction (AMI) that occurred postoperatively. There were three cases that did not fall under the previous two groups that were classified as "others": a case where the surgeon missed synchronous cancer at initial surgery, leading to an additional operation, a case with a fragment of drain retained inside the abdomen due to breakage during attempted removal and a case of device-related error in patient-controlled analgesia. 
Table 2

Complications and other events that led to medical disputes.

\begin{tabular}{|lll|}
\hline Causes of disputes & $\begin{array}{l}\text { No. of patients } \\
(\mathbf{n = 2 0 )}\end{array}$ & \% \\
\hline Surgical complications & 14 & 70.0 \\
\hline Anastomotic leakage & 5 & 25.0 \\
\hline Postoperative bleeding & 2 & 10.0 \\
\hline Mechanical ileus & 5 & 25.0 \\
\hline latrogenic injury of other organs & 2 & 10.0 \\
\hline Medical complications & 3 & 15.0 \\
\hline Anaphylaxis & 2 & 10.0 \\
\hline Acute myocardial infarction & 1 & 5.0 \\
\hline Other events & 3 & 15.0 \\
\hline Intraabdominally retained drain & 1 & 5.0 \\
\hline Incomplete resection due to missed synchronous lesion & 1 & 5.0 \\
\hline Device-related error of PCA & 1 & 5.0 \\
\hline PCA = patient-controlled analgesia & & \\
\hline
\end{tabular}


Table 3

Analysis of the awarded compensation for settlement of medical disputes according to different factors

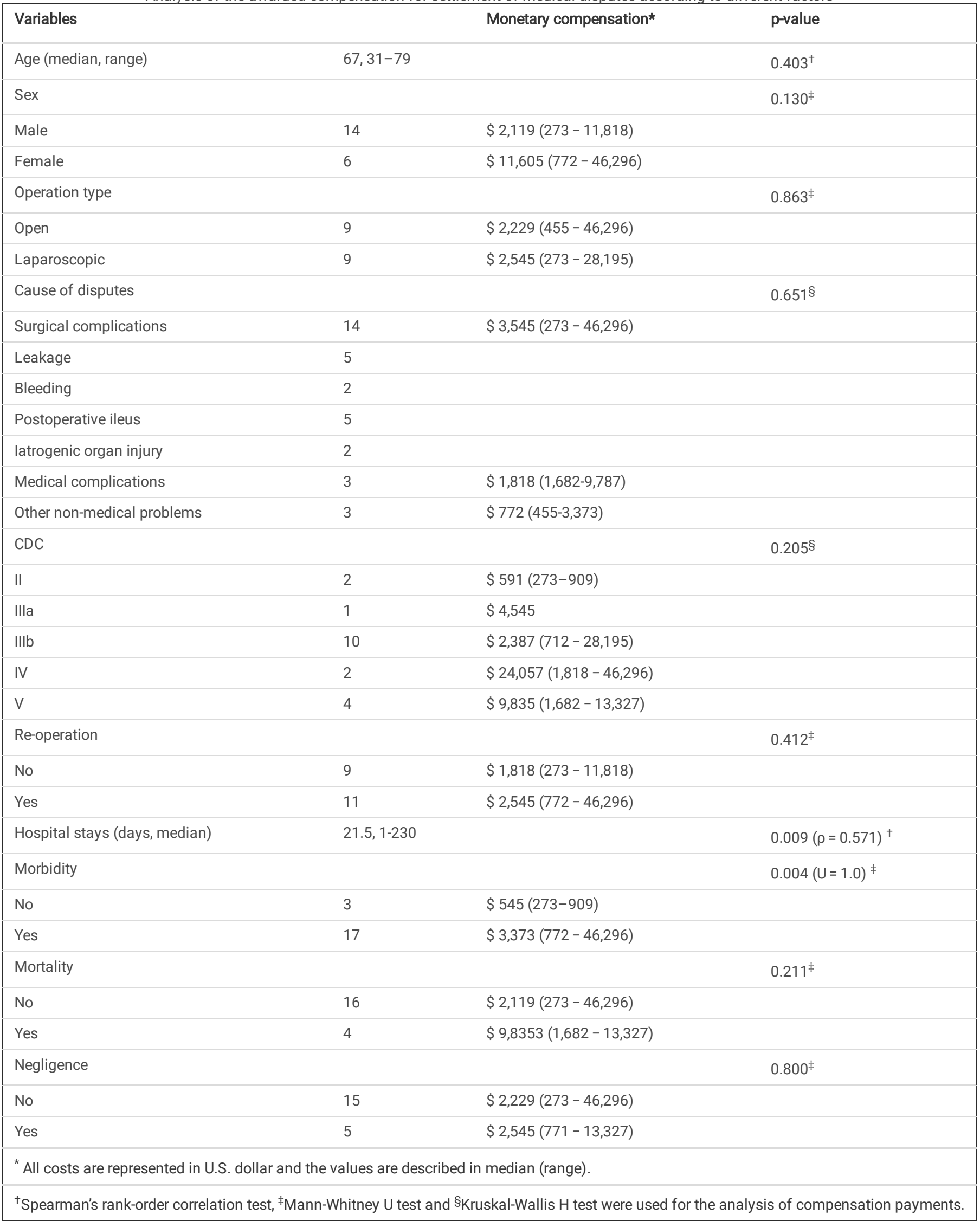

The median and mean monetary compensation for the settlement of medical disputes was USD 2,387 and USD 7,502, respectively, with a range from USD 273 to 46,296 . There was no significant difference in amount of compensation according to age, sex, operation type or the cause of disputes. A total of 19 cases of adverse events excluding a case of patient-controlled analgesia (PCA) error that did not involve any kind of adverse outcome, were graded according to the 
$\mathrm{CDC}$; there was no statistical difference in compensation between different CDC groups. The median hospital stay was 21.5 days with a range from 1 to 230 days, and there was a positive relationship between hospital stays and the amount of awarded compensation with a coefficient of $0.571(p=0.009)$.

There were 17 morbidity cases that involved re-operation or intervention, ICU care or mortality associated with the adverse event. There was a statistically significant difference in awarded compensation according to morbidity $(p=0.004)$. There were four cases of mortality among the study group which included a case of postoperative AMI that led to sudden death of the patient, a case of postoperative luminal bleeding in which the patient died during preparation for an emergency operation and a case of anaphylactic shock during induction of anesthesia, where the patient failed to recover despite immediate cardiopulmonary cerebral resuscitation and extracorporeal membrane oxygenation. Another mortality case involved a patient who was delayed diagnosed with mechanical ileus with bowel ischemia at 90 days since primary gastrectomy and underwent three consecutive operations due to anastomotic failure at the first and second surgeries for ileus and died of sepsis.

Medical negligence was detected in five cases. We determined that a delayed diagnosis in the aforementioned case of mechanical ileus at 90 postoperative days may have resulted in the progression of bowel ischemia and poor surgical results. Another is the case in which a patient had to undergo an additional surgery the day after the initial distal gastrectomy because the surgeon missed and left a synchronous cancer at the stomach fundus. The case of an intraabdominally retained drain and two cases of iatrogenic injury of organs that all required surgery for resolution were also determined to be cases of medical negligence.

\section{Discussion}

The incidence of medical disputes and litigation is growing rapidly in Korea(6), and a similar trend has been observed worldwide(9-11). Most medical disputes usually occur when a patient perceives or is affected by an adverse event(12), although adverse events may not always result from medical negligence. Postoperative complications are inevitable. Failure or delay in identifying these complications is considered as medical negligence; however, despite a prompt diagnosis and appropriate management, there could be a possibility of medical disputes being raised. An extensive study carried out in the United States revealed that adverse events occurred in 3.7\% of hospitalizations, and among them, only $27.6 \%$ were attributed to negligence(13).

The results of our study showed that 19 cases of medical disputes (95.0\%) resulted from adverse events, and among these, five (26.3\%) were consequences of medical negligence. There were other cases where unexpected complications occurred without any evidence of negligence; nevertheless, the medical staff may be held responsible for such results and suffer deleterious economic consequences(14). Our results also demonstrated that the absence of medical negligence was not associated with less compensation.

Morbidity $(p=0.004, U=1.0)$ and length of hospital stay $(p=0.009$, rho $=0.571)$ were factors associated with the amount of compensation. This may result from the higher total medical costs that patients with morbidity and longer hospital stay had to bear, but unfortunately data on patients' medical costs were unavailable due to the retrospective nature of the study.

The mean compensation awarded was USD 7,502 $\pm 2,534$. The Korean Medical Dispute Mediation and Arbitration Agency year book(6) stated that the average cost of mediation in 2016 was USD 7,964 with an annual increase of $7 \%$. Although these data were based on disputes raised in all fields of medicine including Korean medicine and dentistry, the mean total cost was comparable to that of our study, while it was far different from that of data from the US, where an average compensation of USD 485,348 was paid(15). This disparity is due to the difference in patient medical costs. The average overall healthcare cost for gastric cancer was USD 149,900 in Western countries(16) whereas it was USD 12,577 in South Korea(17).

This study has several limitations. This study was a retrospective review and the information on disputes we could receive from the legal affairs team was limited only to cases that involved payment of compensation from the hospital for settlement of the disputes; information on the total medical costs of the patients was unavailable. In addition, this study is based on data from a single large-volume center in Korea; therefore, it may not reflect the situations in care centers of different settings or other countries.

\section{Conclusions}

Despite these limitations, the present study provides foundational information on medical disputes associated with surgery in gastric cancer patients and accompanying compensation costs awarded for settlement, which cannot be obtained from previous literature.

\section{Abbreviations}

CDC, Clavien-Dindo classification; USD, U.S. dollar; AMI, acute myocardial infarction; PCA, patient-controlled analgesia; ICU, intensive care unit

\section{Declarations}

\section{Ethics approval and consent to participate}

The study was approved by the Institutional Review Board of Asan Medical Center (registration number: 2020-0993)

\section{Consent for publication}

Not applicable.

\section{Competing interests}


The authors disclose no potential conflicts of interest.

\section{Availability of data and materials}

The datasets used and/or analyzed during the current study are available from the corresponding author on reasonable request.

\section{Funding}

This study received no funding.

\section{Authors' contributions}

Y.M.W. contributed to conceptualization of the study. K.A. analyzed and interpreted the data and drafted the manuscript. All authors read and approved the final manuscript.

\section{Acknowledgements}

Not applicable.

\section{References}

1. Songun I, Putter H, Kranenbarg EM, Sasako M, van de Velde CJ. Surgical treatment of gastric cancer: 15-year follow-up results of the randomised nationwide Dutch D1D2 trial. Lancet Oncol. 2010/04/23 ed2010. p. 439-49.

2. Papenfuss WA, Kukar M, Oxenberg J, Attwood K, Nurkin S, Malhotra U, et al. Morbidity and mortality associated with gastrectomy for gastric cancer. Annals of surgical oncology. 2014;21(9):3008-14.

3. Li SS, Udelsman BV, Parikh A, Klempner SJ, Clark JW, Roeland EJ, et al. Impact of Postoperative Complication and Completion of Multimodality Therapy on Survival in Patients Undergoing Gastrectomy for Advanced Gastric Cancer. Journal of the American College of Surgeons. 2020;230(6):912-24.

4. Kitano S, Shiraishi N, Uyama I, Sugihara K, Tanigawa N. A multicenter study on oncologic outcome of laparoscopic gastrectomy for early cancer in Japan. Annals of surgery. 2007;245(1):68-72.

5. Kim HH, Hyung WJ, Cho GS, Kim MC, Han SU, Kim W, et al. Morbidity and mortality of laparoscopic gastrectomy versus open gastrectomy for gastric cancer: an interim report-a phase III multicenter, prospective, randomized Trial (KLASS Trial). Annals of surgery. 2010;251(3):417-20.

6. Agency KMDMaA. Medical dispute mediation and arbitration statistical yearbook 2016. 2016.

7. Jung JY, Kim SY, Kim DG, Kim CB, Chi KC, Kang WK, et al. Analysis of lawsuit cases in the Department of Surgery in Korea. Annals of surgical treatment and research. 2018;94(3):113-7.

8. Clavien PA, Barkun J, de Oliveira ML, Vauthey JN, Dindo D, Schulick RD, et al. The Clavien-Dindo Classification of Surgical Complications: Five-Year Experience. Annals of surgery. 2009;250(2):187-96.

9. Wu CY, Weng HC, Chen RC. Time trends of assessments for medical dispute cases in Taiwan: a 20-year nationwide study. Internal medicine journal. 2013;43(9):1023-30.

10. Zeng Y, Zhang L, Yao G, Fang Y. Analysis of current situation and influencing factor of medical disputes among different levels of medical institutions based on the game theory in Xiamen of China: A cross-sectional survey. Medicine (Baltimore). 2018;97(38):e12501-e.

11. Yau CWH, Leigh B, Liberati E, Punch D, Dixon-Woods M, Draycott T. Clinical negligence costs: taking action to safeguard NHS sustainability. BMJ. 2020;368:m552.

12. Jung JY, Kim SY, Kim DG, Kim CB, Chi K-C, Kang WK, et al. Analysis of lawsuit cases in the Department of Surgery in Korea. Annals of surgical treatment and research. 2018;94(3):113-7.

13. Brennan TA, Leape LL, Laird NM, Hebert L, Localio AR, Lawthers AG, et al. Incidence of adverse events and negligence in hospitalized patients. Results of the Harvard Medical Practice Study I. The New England journal of medicine. 1991;324(6):370-6.

14. Aoki N, Uda K, Ohta S, Kiuchi T, Fukui T. Impact of miscommunication in medical dispute cases in Japan. International journal for quality in health care: journal of the International Society for Quality in Health Care. 2008;20(5):358-62.

15. Studdert DM, Mello MM, Gawande AA, Gandhi TK, Kachalia A, Yoon C, et al. Claims, errors, and compensation payments in medical malpractice litigation. The New England journal of medicine. 2006;354(19):2024-33.

16. Casamayor M, Morlock R, Maeda H, Ajani J. Targeted literature review of the global burden of gastric cancer. ecancermedicalscience. $2018 ; 12$.

17. Shin J-Y, Kim S, Lee K-S, Lee S-i, Ko Y, Choi Y-S, et al. Costs During the First Five Years Following Cancer Diagnosis in Korea. Asian Pacific journal of cancer prevention : APJCP. 2012;13:3767-72. 